\title{
BMJ Open Effect of maternal age on facility-based delivery: analysis of first-order births in 34 countries of sub-Saharan Africa using demographic and health survey data
}

\author{
Catherine L Dunlop, ${ }^{1}$ Lenka Benova, ${ }^{2}$ Oona Campbell ${ }^{2}$
}

To cite: Dunlop CL, Benova L, Campbell 0. Effect of maternal age on facility-based delivery: analysis of first-order births in 34 countries of sub-Saharan Africa using demographic and health survey data. BMJ Open 2018;8:e020231. doi:10.1136/ bmjopen-2017-020231

- Prepublication history and additional material for this paper are available online. To view these files, please visit the journal online (http://dx.doi org/10.1136/bmjopen-2017020231).

Received 13 November 2017 Revised 10 January 2018 Accepted 1 February 2018

\section{Check for updates}

1 Institute of Metabolism and Systems Research, University of Birmingham, Birmingham, UK ${ }^{2}$ Department of Infectious Disease Epidemiology and Faculty of Epidemiology and Population Health, London School of Hygiene and Tropical Medicine, London, UK

Correspondence to Dr Catherine L Dunlop; catherinedunlop@nhs.net

\section{ABSTRACT}

Objectives Increasing access to skilled birth attendance, usually via childbirth in health facilities, is a key intervention to reduce maternal and perinatal mortality and morbidity. Yet, in some countries of sub-Saharan Africa, the uptake is $<50 \%$. Age and parity are determinants of facility-based delivery, but are strongly correlated in high fertility settings. This analysis assessed the independent effect of age on facility-based delivery by restricting to first-order births. It was hypothesised that older first-time mothers in this setting might have lower uptake of facilitybased deliveries than women in the most common age groups for first birth.

Setting The most recent Demographic and Health Surveys from 34 sub-Saharan African countries were used to assess women's delivery locations.

Participants 72772 women having their first birth in the 5 years preceding the surveys were included in the analysis.

Primary and secondary outcome measures Proportions and $95 \%$ Cls of facility-based deliveries were estimated overall and by country. Multivariable logistic regression was used to calculate the odds of facility-based delivery for different maternal age groups (15-19, 20-24 and $\geq 25$ years) for a pooled sample of all countries.

Results $59.9 \%$ of women had a facility-based delivery for their first birth $(95 \% \mathrm{Cl} 58.6$ to 61.2$)$, ranging from $19.4 \%$ in Chad to $96.6 \%$ in Rwanda. Compared with women aged 15-19 years, the adjusted odds of having a facility-based delivery for those aged 20-24 was 1.4 (95\% Cl 1.3 to 1.5 , $\mathrm{p}<0.001)$ and for those aged $\geq 25,1.9(95 \% \mathrm{Cl} 1.6$ to 2.2 , $\mathrm{p}<0.001)$

Conclusions Older age at first birth was independently associated with significantly higher odds of facility-based delivery. This went against the hypothesis. Further mixedmethod research is needed to explore how increased age improves uptake of facility-based delivery. Promoting facility-based delivery, while ensuring quality of care, should be prioritised to improve birth outcomes in subSaharan Africa.

\section{INTRODUCTION}

Most maternal and neonatal deaths cluster around the day of birth. ${ }^{1}$ It is difficult to predict which women will suffer complications $^{2}$ as they often occur rapidly without

\section{Strengths and limitations of this study}

- This is the first known study to look at the effect of increasing age at first motherhood on facility-based delivery uptake in sub-Saharan Africa, having adjusted for parity by restricting to first-order births.

- This study benefits from a very large population size of 72772 women in 34 countries using Demographic and Health Surveys data, which is high quality, comprehensive and nationally representative, thus giving our results high external validity, the ability to analyse rare events such as older age at first birth, and to adjust for multiple variables.

- Uptake of facility-based deliveries is important to understand in sub-Saharan Africa, because of the high maternal mortality ratio, while older age at first motherhood is a rare outcome in sub-Saharan Africa and has not been previously examined with such a large dataset and population coverage.

- The adjusted relationship between age and facility-based delivery was only examined for the pooled dataset and not for individual countries. This was because of the rarity of women being $\geq 25$ years old at first birth in the population.

- We were unable to adjust for the quality of care in health facilities within women's reach, which may alter motivations to have a facility-based delivery, and the subsequent maternal and perinatal outcomes.

warning. ${ }^{3}$ To save maternal and perinatal lives, skilled attendance at birth and access to a facility that provides Comprehensive Emergency Obstetric and Newborn Care are critical requirements for all labouring women ${ }^{4}$. Most skilled attendants work in health facilities, and skilled attendance at birth was an indicator for Millennium Development Goal 5. ${ }^{4}$ Despite this international focus, less than $50 \%$ of deliveries are facility based in many countries of sub-Saharan Africa, ${ }^{5}$ and coverage among poor women is even lower. ${ }^{6}$ Understanding why women fail to use facilities for delivery is 
essential to improve uptake of these services through targeted interventions. ${ }^{5}$

Multiple social and economic factors affect uptake of facility-based delivery. If anticipated quality of care is low, this may act as a barrier to facility-based delivery. ${ }^{5-9}$ Poorer families are less likely to have facility-based deliveries because of problems funding transport, user fees and hidden costs of treatments. ${ }^{2}{ }^{5-7}$ Antenatal care (ANC) is associated with increased uptake of facility-based delivery, ${ }^{57}$ as is urban residence ${ }^{510-12}$ and increased time in education for the woman. ${ }^{510}$ The impact of a woman's 'autonomy' on facility-based delivery uptake is inconsistent in the literature. ${ }^{2} 5713$ However, a women's education and employment may increase her autonomy within a household, ${ }^{14}$ in turn increasing her capacity and self-efficacy in decisions regarding her delivery location.

\section{Impact of age and parity on facility-based delivery}

It is important to understand the individual impacts of age and parity for multiple reasons. In high fertility settings, such as most countries of sub-Saharan Africa, older women are more likely to be of high parity ${ }^{7}$ and higher parity is consistently associated with reduced facility-based deliveries. ${ }^{25711}$ This indicates that the first birth is most likely to be facility based. This may be because women develop confidence in childbirth through experience, so prefer to stay at home with higher order births, ${ }^{13}$ or demands of household duties, childcare and financial strain may be a barrier to facility-based delivery for higher order births. ${ }^{7}$ Younger mothers may desire to follow modern trends, and be so more likely to use facility-based delivery, ${ }^{5} 715$ whereas older mothers may desire more traditional practices. ${ }^{7}$

However, studies which adjust for parity mainly conclude that older age at motherhood is associated with increased odds of facility-based delivery. ${ }^{10}{ }^{16}$ Despite this, some reviews show inconsistent results, ${ }^{7}$ no effect of age ${ }^{11}$ or decreased use with age unless the woman was younger than $18 .^{5}$ Older motherhood is associated with wealth, education, marriage, wanted pregnancies, ${ }^{7}$ multiple births, known health problems and complications of labour. ${ }^{17}$ All of these factors have been shown to increase facility-based delivery. ${ }^{571016}$

Yet, it is also plausible that in settings where fertility is valued, as in much of sub-Saharan Africa, ${ }^{18}{ }^{19}$ women having their first birth at older ages could have a delayed first birth for reasons related to social exclusion, or be socially excluded as a consequence of a delayed first birth. ${ }^{20}$ Women suffering health complications, developmental delays, mental health problems or disadvantage may have experienced a delay in partnership or pregnancy and therefore not had a child within the age range considered the sociocultural 'norm'. Second, recurrent pregnancy losses, later selection for marriage or difficulty conceiving may mean women are stigmatised in a setting where fertility is highly prised. ${ }^{18-20}$ If disadvantage or social stigma arose from or contributed to an older age at first birth, such women may experience increased barriers to facility-based delivery. ${ }^{2}$

The strong correlation between age and parity makes it difficult to demonstrate the individual impact of each factor $^{7}$ on uptake of facility-based delivery. There is a gap in the literature for understanding the influence of older age on facility-based delivery, a rare outcome in sub-Saharan Africa, having removed the effect of parity. Understanding the impact of age at first birth is particularly important, as first births are more susceptible to adverse outcomes for mother and child. ${ }^{21}$ Additionally, the experience in the first birth may determine the future healthseeking behaviours of that mother. ${ }^{10}$

\section{Objective}

This multicountry analysis of first-order births aims to assess the effect of age on facility-based delivery uptake in first-time mothers in sub-Saharan Africa. We hypothesised that older first-time mothers in a setting where fertility is highly valued ${ }^{1822}$ may be a marginalised group and therefore might have lower uptake of facility-based delivery than women in the most common age groups for first birth.

\section{METHODS}

\section{Data source}

Demographic and Health Surveys (DHS) are nationally representative, cross-sectional household surveys. Typically, around 5000-30 000 households are sampled using a multilevel cluster survey design ${ }^{23}$ and most information is obtained by individuals' self-report. ${ }^{23-25}$ The questionnaires are adapted for different settings but are comparable between countries. ${ }^{24}$ There is a module conducted on women's reproductive health for those aged 15-49, including a review of each birth history. ${ }^{26}$

\section{Definitions}

Sample: The most recent DHS available at the time of analysis (July 2016) were used, if conducted since 2000. Women aged 15-49 who had their first live birth in the 5 years preceding the survey were included in the analysis. Therefore, first births occurring to women from the age of 11 were included in the analysis. Descriptive analysis was performed using women's age in 5-year age groups at the time of first birth. Due to very small numbers in the most extreme age groups, the crude and adjusted analyses were done using a categorical age variable of 15-19, 20-24 and $\geq 25$, to compare 'older' mothers $(\geq 25)$ with the most common ages for first births (15-19 and 20-24). Girls aged 11-14 at time of first birth were excluded from the regression analysis, because they represented an unusual group of women for different reasons than those giving birth aged $\geq 25$ and, they did not represent the majority of 'younger' first-time mothers to contribute to a comparison group.

Outcome (delivery location): Women's delivery locations were categorised into home, facility or other 
(unknown) locations based on previous DHS analysis by Benova $e t$ al. ${ }^{25}$ Women with 'unknown' delivery locations were excluded from multivariable analysis.

Other covariates: Contraceptive need was grouped into three categories: 'unmet need'; 'met need' (women using modern contraceptives, infecund, menopausal or not sexually active) and 'unknown' need based on algorithms applied by DHS. ${ }^{27}$ Marital status was categorised as never married, currently married (including cohabiting couples) and 'formerly married'. 'Wantedness' of the child was grouped into wanted 'then', 'later' meaning preferred at a later date and 'none', meaning the woman wanted no children. 'Maternal education' described the highest level started by each woman. 'Residence' described if the women lived in an urban or rural area. 'Multiple birth' described if the first birth was a singleton delivery or multiple. 'Wealth quintile' was categorised as poorest, poorer, middle, richer and richest. This described the asset index quintile that the woman falls into, comparing her asset ownership to the population of her individual country of residence. Finally, 'ANC uptake' described if the woman accessed any ANC provision during the pregnancy described. ANC care uptake is asked in DHS only for the latest birth in the survey recall period, that is, if the woman had more than one birth in the recall period, this variable was only available for the most recent birth. Therefore, in this analysis of first births the ANC variable was only available for women who had had exactly one birth in the recall period.

\section{Analysis}

Analysis was conducted using Stata SE V.14. Descriptive and crude analysis was conducted by country, and descriptive, crude and adjusted analysis for sub-Saharan Africa overall. The country-level analysis was conducted using weight, clustering and stratification variables provided by DHS, using the svyset command, to account for the study design. The sub-Saharan Africa pooled analysis additionally used a country-specific weight calculated from comparative population sizes at the median year of the surveys (2012).

For descriptive analysis, characteristics of women having their first births in sub-Saharan Africa were described as a whole and for each country using proportions and 95\% CIs. Factors associated with both age at first birth and facility-based delivery were considered possible confounders.

The multivariable model was built through a forward stepwise approach. Multivariable models included fixed effect for country. Multiple birth was not adjusted for, as it was hypothesised to be on the causal pathway between older age at first birth and facility-based delivery (as older age has been found to be associated with multiple births ${ }^{17}$ and women known to be having multiple births are more likely to deliver in a facility ${ }^{10}$ ). Multiple births accounted for a very small percentage of the study population $(1.05 \%)$.

A second multivariable analysis of women with exactly one (first) live birth in the recall period was conducted to adjust for confounding by ANC use (only measured for most recent live birth in the survey recall period), using the same approach.

\section{Missing data}

There were no missing data in women's ages at first birth. Women with missing data on delivery location $(1.9 \%$ of the pooled sample) and those aged 11-14 (2.1\% of the pooled sample) were excluded from the analysis. Women with missing data in any other variable (3.6\% of pooled sample) were excluded from the logistic regression analysis only. Further information on missing data in each covariate is included in online supplementary material 1 .

\section{Ethics}

DHS work within agreed limits of the national government in each country setting. Respondents are asked for verbal consent to participate and all results are anonymised. ${ }^{28}$

\section{RESULTS}

\section{Summary of setting}

At the time of analysis, 34 countries in sub-Saharan Africa had a DHS conducted since 2000, so were included in the analysis. Table 1 and figure 1 describe the 72772 women who were included in the analysis sample. The women's ages at first birth ranged from 11 to 47 years old. The most common age groups for first births in every country were $15-19$ or 20-24. The percentage of women having their first birth aged $\geq 25$ years ranged from $3.9 \%$ in Chad to $33.4 \%$ in Comoros. Overall, $59.9 \%$ of women had a facility-based delivery for their first birth (95\% CI 58.6 to 61.2). This ranged from $19.4 \%$ in Chad to $96.6 \%$ in Rwanda.

Further descriptive analysis of women's characteristics is included in online supplementary material 1 .

\section{Crude odds of facility-based delivery and age at first birth using the categorical age variable}

In the pooled sample of women from all countries, $52.1 \%$ of women aged $15-19$ had a facility-based delivery for their first birth, compared with $64.9 \%$ of those aged 20-24years and $78.7 \%$ of those aged $\geq 25$. With older age at first birth, there was increased crude odds of facility-based delivery for sub-Saharan Africa overall. Compared with those aged 15-19, women giving birth aged 20-24 had 1.7 times the crude odds of facility-based delivery (95\% CI 1.6 to $1.9, \mathrm{p}<0.0001$ ), and those aged $\geq 25$ had 3.5 times the crude odds (95\% CI 3.1 to $4.0, \mathrm{p}<0.0001)$, as shown in table 2 .

Table 2 also shows that in 18 countries, we found strong evidence of an increase in crude odds of facility-based delivery with older age at first birth. The most pronounced increases in crude odds when compared with regional population-weighted averages were in Cameroon, Kenya, Nigeria and Swaziland. No country showed significant evidence of decreasing odds of facility-based delivery with increasing age at first birth. 
Table 1 The characteristics of women having their first birth, in sub-Saharan Africa and by country

\begin{tabular}{|c|c|c|c|c|c|c|c|c|c|}
\hline \multirow{2}{*}{$\begin{array}{l}\text { Country (survey } \\
\text { year) }\end{array}$} & \multirow[b]{2}{*}{$\mathbf{n}^{*}$} & \multicolumn{7}{|c|}{ Percentage of first births in recall period by maternal age } & \multirow{2}{*}{$\begin{array}{l}\text { Facility-based delivery } \\
(\% \text { and } 95 \% \mathrm{Cl}) \dagger\end{array}$} \\
\hline & & 11-14 & $15-19$ & $20-24$ & $25-29$ & $30-34$ & $35-39$ & $40-49$ & \\
\hline $\begin{array}{l}\text { Sub-Saharan } \\
\text { Africa (median }\end{array}$ & & & & & & & & & \\
\hline $\begin{array}{l}\text { 2012) } \\
\text { Benin (2011) }\end{array}$ & $\begin{array}{r}72772 \\
2679\end{array}$ & $\begin{array}{l}2.10 \\
1.39\end{array}$ & $\begin{array}{l}50.17 \\
35.96\end{array}$ & $\begin{array}{l}34.14 \\
42.44\end{array}$ & $\begin{array}{l}10.40 \\
16.09\end{array}$ & $\begin{array}{l}2.56 \\
2.78\end{array}$ & $\begin{array}{l}0.55 \\
1.13\end{array}$ & $\begin{array}{l}0.08 \\
0.22\end{array}$ & $\begin{array}{l}59.89(58.59 \text { to } 61.18) \\
90.25(88.26 \text { to } 91.94)\end{array}$ \\
\hline $\begin{array}{l}\text { Burkina Faso } \\
\text { (2010) }\end{array}$ & 2813 & 0.62 & 58.90 & 32.36 & 7.06 & 0.96 & 0.10 & 0.00 & 76.47 (73.42 to 79.27$)$ \\
\hline Burundi (2010) & 1619 & 0.38 & 34.13 & 50.78 & 11.88 & 2.33 & 0.50 & 0.00 & 77.22 (74.53 to 79.70$)$ \\
\hline Cameroon (2011) & 2679 & 3.83 & 53.58 & 31.89 & 8.92 & 1.25 & 0.52 & 0.00 & 73.53 (69.29 to 77.37$)$ \\
\hline Chad (2004) & 1016 & 6.44 & 67.89 & 21.79 & 3.42 & 0.35 & 0.03 & 0.08 & 19.37 (14.47 to 25.44$)$ \\
\hline Comoros (2012) & 698 & 1.36 & 34.10 & 31.13 & 19.97 & 10.57 & 2.71 & 0.18 & 86.49 (83.08 to 89.30$)$ \\
\hline Congo-B (2012) & 2028 & 2.12 & 55.06 & 29.00 & 10.82 & 2.34 & 0.61 & 0.04 & 93.53 (91.63 to 95.03$)$ \\
\hline Ivory Coast (2012) & 1694 & 3.17 & 51.45 & 33.39 & 9.47 & 1.57 & 0.81 & 0.15 & 66.11 (61.82 to 70.16$)$ \\
\hline DRC (2014) & 3573 & 2.34 & 53.13 & 33.76 & 8.85 & 1.65 & 0.27 & 0.00 & 77.00 (73.57 to 80.11$)$ \\
\hline Ethiopia (2011) & 2303 & 1.19 & 45.86 & 42.04 & 8.17 & 2.06 & 0.68 & 0.00 & 20.96 (17.26 to 25.21$)$ \\
\hline Gabon (2012) & 1479 & 3.12 & 50.31 & 29.38 & 12.75 & 2.81 & 1.48 & 0.14 & 90.85 (87.78 to 93.21$)$ \\
\hline Gambia (2013) & 1731 & 1.55 & 45.02 & 37.13 & 13.16 & 2.84 & 0.19 & 0.11 & 78.66 (74.24 to 82.50$)$ \\
\hline Ghana (2014) & 1335 & 0.55 & 32.41 & 35.75 & 22.05 & 7.36 & 1.60 & 0.29 & 83.81 (80.19 to 86.88 ) \\
\hline Guinea (2012) & 1526 & 5.50 & 60.74 & 24.60 & 7.30 & 1.37 & 0.40 & 0.09 & 50.00 (45.10 to 54.90$)$ \\
\hline Kenya (2014) & 4804 & 1.10 & 40.28 & 42.24 & 13.75 & 1.91 & 0.59 & 0.13 & 78.47 (76.54 to 80.29$)$ \\
\hline Lesotho (2009) & 1494 & 0.81 & 46.55 & 41.69 & 7.89 & 2.26 & 0.62 & 0.17 & 73.53 (70.11 to 76.68$)$ \\
\hline Liberia (2013) & 1595 & 2.61 & 62.94 & 27.71 & 5.90 & 0.65 & 0.00 & 0.18 & 64.11 (59.78 to 68.22$)$ \\
\hline $\begin{array}{l}\text { Madagascar } \\
\text { (2009) }\end{array}$ & 2887 & 4.64 & 58.06 & 27.34 & 7.17 & 2.04 & 0.55 & 0.20 & 41.82 (38.45 to 45.26$)$ \\
\hline Malawi (2010) & 3925 & 1.30 & 64.48 & 30.08 & 3.45 & 0.50 & 0.20 & 0.00 & 81.65 (79.28 to 83.80$)$ \\
\hline Mali (2013) & 1879 & 6.09 & 57.84 & 25.55 & 8.26 & 1.87 & 0.36 & 0.02 & 61.31 (57.20 to 65.28$)$ \\
\hline $\begin{array}{l}\text { Mozambique } \\
\text { (2011) }\end{array}$ & 2537 & 3.15 & 63.18 & 26.66 & 5.40 & 1.25 & 0.30 & 0.06 & 64.18 (60.47 to 67.74$)$ \\
\hline Namibia (2013) & 1617 & 0.69 & 39.75 & 40.40 & 13.81 & 4.00 & 1.23 & 0.13 & 93.16 (91.57 to 94.47$)$ \\
\hline Niger (2012) & 1860 & 3.64 & 66.24 & 22.61 & 6.60 & 0.89 & 0.01 & 0.00 & 42.94 (39.22 to 46.74$)$ \\
\hline Nigeria (2013) & 6108 & 2.22 & 46.40 & 32.20 & 14.27 & 4.06 & 0.77 & 0.08 & 47.21 (44.21 to 50.24$)$ \\
\hline Rwanda (2015) & 2322 & 0.20 & 22.21 & 52.06 & 20.32 & 4.12 & 1.07 & 0.03 & 96.63 (95.64 to 97.40$)$ \\
\hline $\begin{array}{l}\text { Sao Tome and } \\
\text { Principe (2009) }\end{array}$ & 389 & 1.16 & 53.01 & 37.57 & 6.72 & 0.99 & 0.55 & 0.00 & 91.14 (87.06 to 94.03$)$ \\
\hline Senegal (2014) & 1418 & 0.79 & 41.10 & 33.36 & 17.02 & 6.06 & 1.15 & 0.52 & 87.87 (84.12 to 90.84$)$ \\
\hline $\begin{array}{l}\text { Sierra Leone } \\
\text { (2013) }\end{array}$ & 2666 & 3.90 & 58.83 & 28.24 & 7.61 & 1.03 & 0.32 & 0.07 & 61.99 (58.36 to 65.49$)$ \\
\hline Swaziland (2006) & 886 & 1.61 & 59.06 & 32.31 & 5.40 & 1.42 & 0.19 & 0.00 & 85.38 (82.67 to 87.73$)$ \\
\hline Tanzania (2010) & 1577 & 1.33 & 56.49 & 33.26 & 6.57 & 2.07 & 0.25 & 0.04 & 67.31 (63.04 to 71.30$)$ \\
\hline Togo (2014) & 1535 & 1.12 & 32.70 & 44.46 & 15.66 & 5.13 & 0.78 & 0.14 & 81.98 (79.02 to 84.59$)$ \\
\hline Uganda (2011) & 1460 & 1.59 & 58.10 & 34.18 & 5.29 & 0.84 & 0.00 & 0.00 & 73.13 (69.57 to 76.42$)$ \\
\hline Zambia (2014) & 2855 & 1.11 & 65.19 & 25.68 & 6.13 & 1.67 & 0.21 & 0.00 & 81.06 (78.83 to 83.11$)$ \\
\hline Zimbabwe (2011) & 1785 & 0.91 & 49.70 & 39.41 & 7.83 & 1.73 & 0.27 & 0.14 & 73.98 (70.85 to 76.89$)$ \\
\hline
\end{tabular}

Darkest green highlights the highest proportion within that row, relevant to each covariate. The colour grading becomes lighter with each successive drop in proportion, with the smallest proportion shaded the lightest colour.

*Unweighted count data used. Weighted proportions used thereafter.

†If a delivery was not facility based, it may be 'Home' or 'Unknown', where missing values are included in 'Unknown'. 


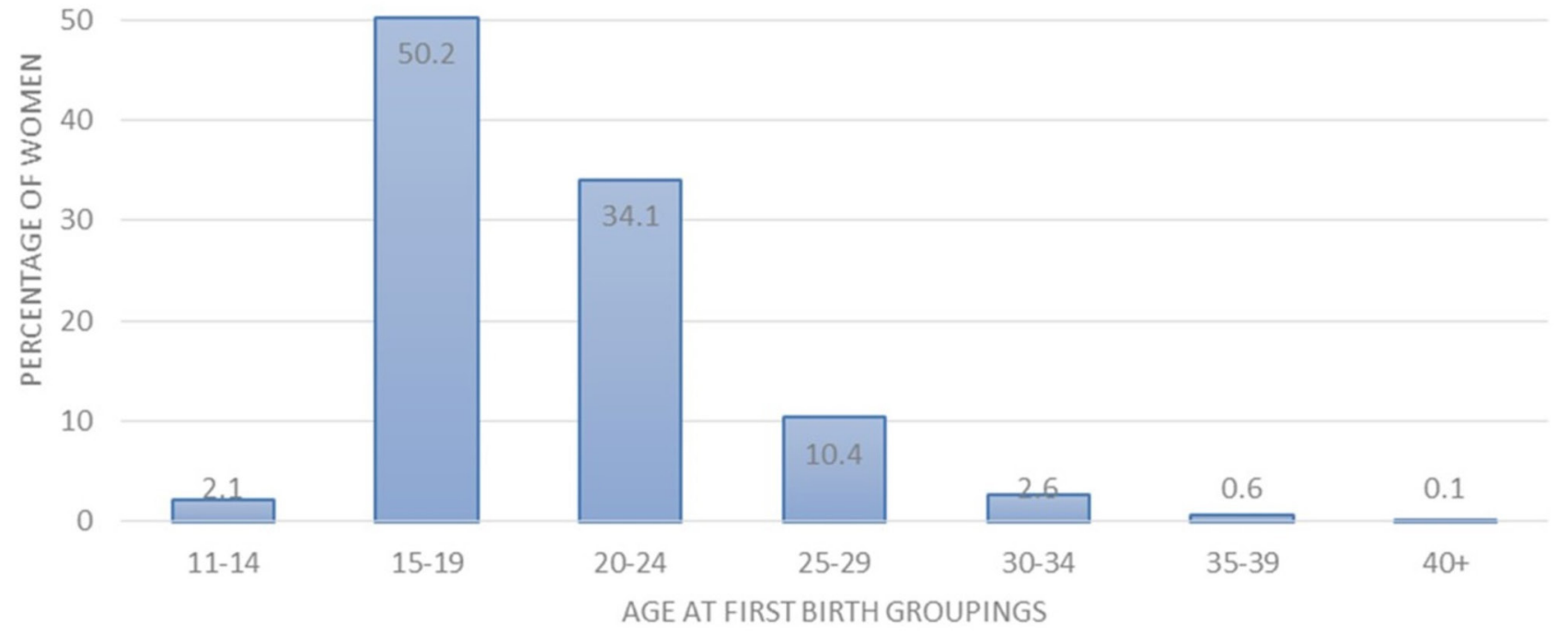

Figure 1 Histogram of pooled age distributions of age at first birth for 34 included sub-Saharan African countries.

\section{Multivariable analysis}

Sixty seven thousand three hundred and sixty women were included in the multivariable complete case analysis. The logistic regression model was adjusted for wantedness of the child, marital status, wealth quintile, maternal education, residence and country. Compared with those aged $15-19$, the adjusted odds of facility-based delivery was 1.4 for those aged 20-24 (95\% CI 1.3 to $1.5, \mathrm{p}<0.0001)$ and 1.9 for those aged $\geq 25$ (95\% CI 1.6 to $2.2, \mathrm{p}<0.0001$ ).

For women having exactly one singleton live birth in the recall period, 43905 observations were included in a second logistic regression analysis. After having adjusted for the same factors as the first multivariable analysis, the odds of facility-based delivery were 1.5 (95\% CI 1.3 to $1.6, \mathrm{p}<0.0001)$ for those aged $20-24$ and 1.9 (95\% CI 1.7 to $2.3, \mathrm{p}<0.0001$ ) for those aged $\geq 25$, compared with those 15-19. After additionally adjusting for use of ANC, the odds of facility-based delivery were 1.4 (95\% CI 1.2 to $1.5, \mathrm{p}<0.0001)$ for those aged $20-24$ and 1.8 (95\% CI 1.5 to $2.1, \mathrm{p}<0.0001$ ) for those aged $\geq 25$. This is shown in table 3 .

\section{DISCUSSION}

This is the first study to look at a large number of sub-Saharan African countries and examine the independent effect of increasing age at first birth on facility-based delivery for the pooled country sample. Our findings showed that, overall in sub-Saharan Africa, $59.9 \%$ of women had a facility-based delivery for their first birth (95\% CI 58.6 to 61.2). Counter to our hypothesis, adjusted analyses showed strong evidence of increasing likelihood of facility-based delivery with older age group at first birth, which remained after adjustment for ANC use. This analysis benefited from high quality, comprehensive, recent, nationally representative data. Use of a large sample size enabled statistical power to analyse rare events, such as older age at first birth, and allowed adjustment for multiple variables in the multivariable analysis. These factors mean our findings have high external validity.

\section{Limitations}

The multivariable analysis was limited by exclusion of some countries in sub-Saharan Africa because they had not had a DHS in the time frame. The pooled country analysis meant some DHS were as recent as 2015, and others as early as 2004. Additionally, the adjusted relationship between age and facility-based delivery was only examined for the pooled dataset and not for individual countries. If the association was in the opposite direction in a country with a relatively small population, this may have been concealed by the associations in larger countries due to population weighting in pooled analysis. Individual country analysis was not done because older age at first birth was a rare event in this population. However, a fixed effect for country was in the adjusted models.

We were not able to adjust for women who had previous pregnancies ending in abortion or stillbirth, as these data are not collected uniformly across countries and are often under-reported. Previous negative experiences of pregnancy or the health system may affect health-seeking behaviours, so would be important confounders to adjust for in future analyses. As DHS does not record this, we were also unable to adjust for gestation of pregnancy at the time of delivery, which could influence uptake of facility-based delivery. We additionally acknowledge the possibility of covariate 
Table 2 Crude ORs of facility-based delivery for first birth by age, for each country

\section{Crude OR of facility-based delivery, using $15-19$ as reference*}

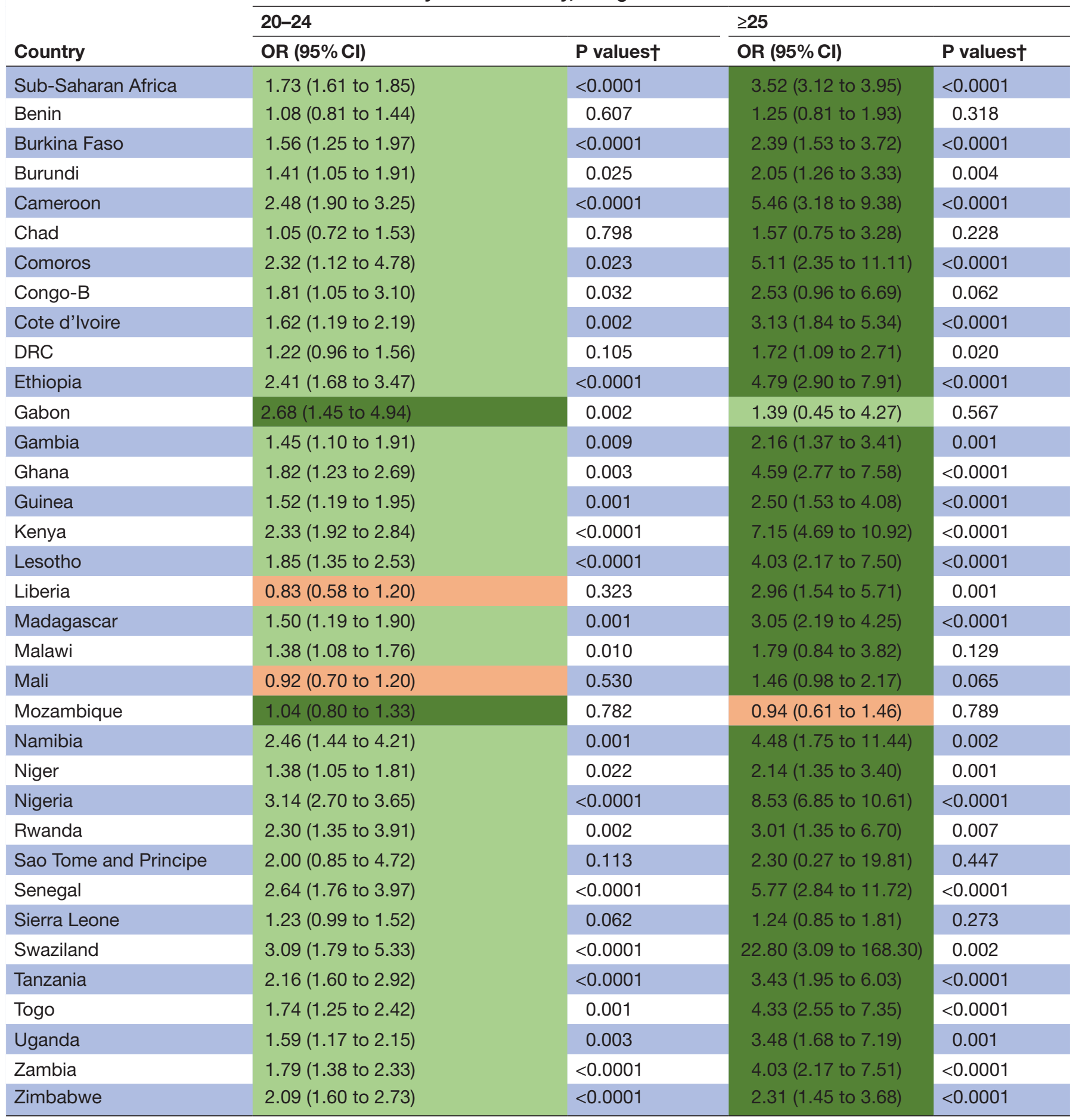

Green indicates increased odds of facility-based delivery compared with those aged 15-19. Darkest green highlights the highest increase in odds of facility-based delivery within that row, compared with those aged 15-19. Orange indicating reduced odds of facility-based delivery compared with those aged 15-19.

${ }^{*}$ Done after dropping $11-14 \mathrm{~s}$ and unknown delivery location.

†Wald test $p$ value.

misclassification in the analysis, as DHS report values at the time of the survey rather than the time of birth. However, we expect most factors to remain stable for most women in the period between birth and the survey date, a maximum 5-year period, so this is unlikely to have influenced the conclusions drawn. Finally, we were not able to adjust for the quality of care in health facilities within women's reach, which may significantly alter motivations and opportunities to have a facility-based delivery, and consequently maternal and newborn 
Table 3 Adjusted OR between age at first birth and facility-based delivery, adjusting for all factors in the table and country

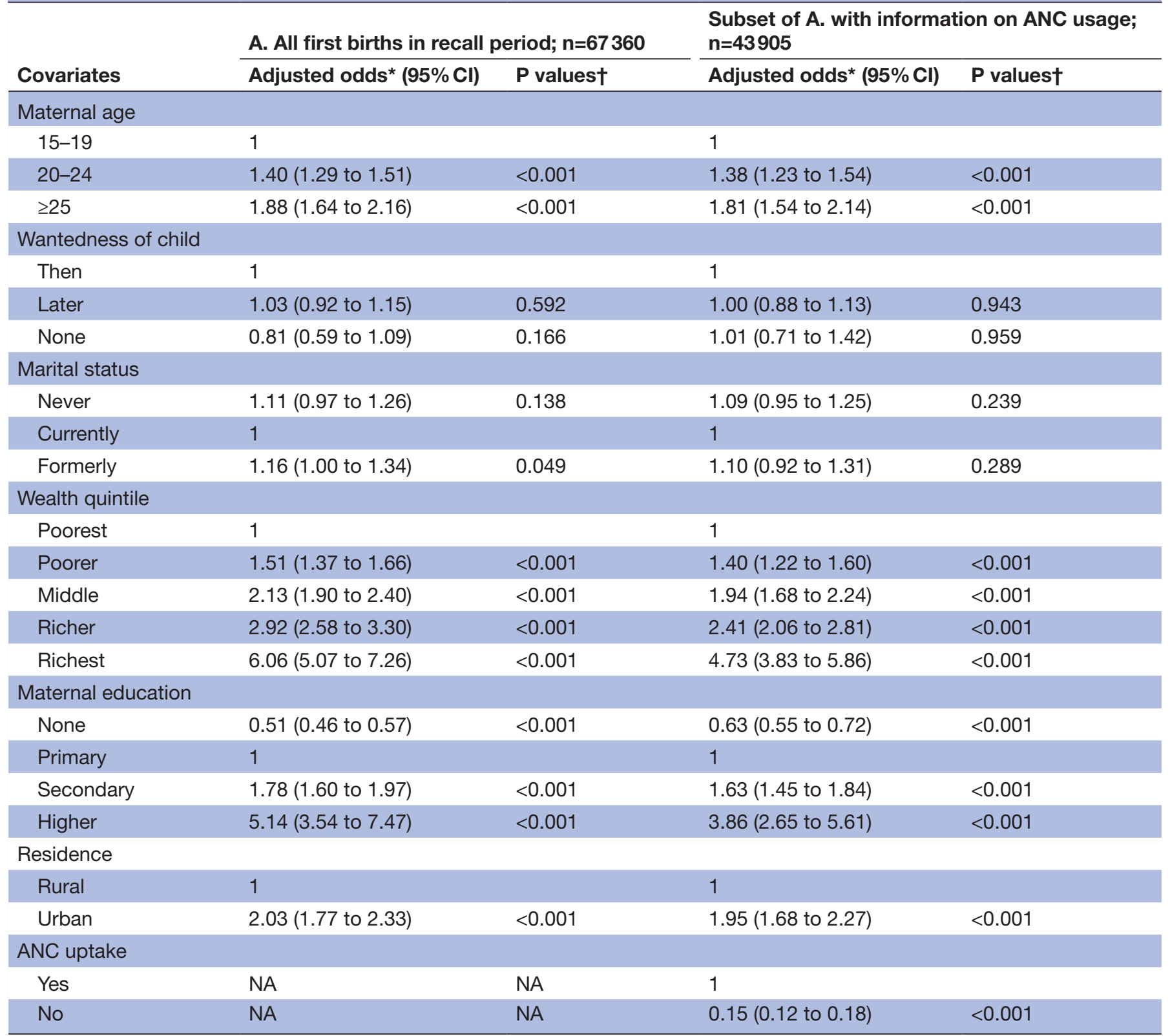

A; includes subjects with no missing data aged 15-49. Subset of A; includes subjects having exactly one singleton live birth in the recall period, meaning singleton births only were included, aged 15-49.

${ }^{*}$ Adjusted for all other factors in the table and country.

†Wald test $p$ value.

ANC, antenatal care; NA, not applicable.

health outcomes. However, quality of care may be adjusted for by proxy, to some extent, through other variables; namely country, residence and ANC uptake.

\section{Interpretation}

Overall, this analysis found that women having their first birth aged 25 years or older were more likely to deliver in a health facility. Reasons suggested for this phenomenon may include increased autonomy to make household decisions with age, an increased awareness of risk of childbirth or greater confidence in using the health system. ${ }^{7}$
Our findings fit with some previous research, showing that increasing age is associated with facility-based delivery in sub-Saharan Africa. ${ }^{10}{ }^{16}$ However, it is counter to other findings of inconsistent relationships with age, ${ }^{7}$ no effect of age ${ }^{11}$ or decreased uptake with age unless the woman was younger than $18 .{ }^{5}$ Our analysis added to this research base by focussing specifically on associations with older age at first birth, only looking at sub-Saharan African countries and additionally analysed a larger number of countries. Our findings go against the original hypothesis that older first-time mothers have 
lower uptake of facility-based delivery. The beneficial impact of household wealth, women's education, urban residence and ANC usage on facility-based delivery fits with previous findings. ${ }^{11}$ As one of the functions of ANC is to promote facility-based delivery, especially for primiparous women,${ }^{29}$ it is expected that these women have higher uptake of facility-based delivery. Women who have successfully accessed ANC have also demonstrated in doing so that they have reduced barriers or greater motivation to use the formal health system than other women may face. ${ }^{1429}$ However, the increased odds of facility-based delivery with older age at first birth remained despite adjusting for these factors.

One pooled DHS analysis looking at switching between facility and home delivery locations, which included 30 countries in sub-Saharan Africa, found that the peak age for odds of facility-based delivery was at ages 25-29, and at older and younger ages the odds of delivering in facility were lower. However, the study still found that those aged $>29$ were more likely than those $<24$ to deliver in a facility. ${ }^{10}$ This broadly fits with our findings, but we have been unable to confirm or refute the pattern of decrease in use of facility-based delivery for specific age categories above the age of 29 , due to the rarity of this outcome for first births. The study in question also concluded that older mothers were more likely to have first births in facility than younger mothers, and less likely to switch delivery location for subsequent births than younger mothers. ${ }^{10}$ However, this indicates that if their first birth was at home, they would be most likely to continue this delivery practice with subsequent births, whereas younger mothers would be more susceptible to switching. ${ }^{10}$

It is notable that we found that only $13.6 \%$ of first births were to women 25 years or older and $3.3 \%$ over the age of 30 for sub-Saharan Africa as a whole. The low proportions of first-order births occurring to women older than the modal age groups meant that our comparative group of 'older age at first birth' $(\geq 25)$ had to include a wide range of ages due to the relative rarity of this outcome. Much has been said about increasing age at first birth in high-income countries, ${ }^{17}{ }^{30}$ but our analysis has not demonstrated this in sub-Saharan Africa.

As a result of our findings, we recommend prioritisation of interventions to promote factors associated with later age at first birth, such as increasing education for girls and access to family planning services to allow women to time their pregnancies. ${ }^{31}$ These interventions would aim to increase rates of facility-based delivery. Such interventions must focus on the rural poor, who currently have lower rates of facility-based delivery and younger ages at first birth.

Second, further research is needed in sub-Saharan Africa to understand the mechanisms by which increasing age acts to encourage facility-based delivery. This should include a more detailed breakdown of age to include first births to women aged $\geq 30$, and the impact of age on higher order births. Factors hypothesised to be relevant include maternal health status, intentions for delivery location during pregnancy and how these change with age. ${ }^{5}$ Qualitative methods may be more appropriate to examine such factors. If gains of age are more clearly understood, then they could be taught as an intervention to younger women to help increase access to facilities. This could be delivered through ANC, which this analysis has shown as high coverage in sub-Saharan Africa (proportions of uptake by country are included in online supplementary material 1 ).

Finally, it is essential that quality of care in facilities is addressed to truly see improvement in maternal and perinatal outcomes, ${ }^{491415}$ in addition to access to services. Better quality of care may actually encourage more women to attend, ${ }^{28}$ as well as improving outcomes, ${ }^{4}$ and will reduce the delay to appropriate care once having reached a facility. ${ }^{22}$ In order to ensure this is prioritised, quality indicators must be developed and monitored in facility settings worldwide and acted on at a national and international level. ${ }^{414}$

\section{CONCLUSIONS}

This paper has shown that among women having their first birth in sub-Saharan Africa, being older is associated with higher likelihood of delivering in a facility. However, even among older first-time mothers, facility-based delivery uptake is far from universal. We have shown that women are most commonly having their first birth between the ages of 15 to 19 in sub-Saharan Africa. Given the increased risks of primiparity ${ }^{21}$ and young age at birth, ${ }^{1632}$ prioritising care for these women is important to improve outcomes. This analysis has also shown that there is a long way to go before all women are having facility-based deliveries in sub-Saharan Africa.

Contributors CLD conducted the literature search, data analysis and written draft of the manuscript. The dataset was compiled by LB, who also provided the pooled weights. Support from OC and LB was given for the theoretical framework of analysis, the analysis itself, presentation and results and interpretation. $O C$ and LB also edited and approved the written draft.

Funding This research received no specific grant from any funding agency in the public, commercial or not-for-profit sectors.

Competing interests None declared.

Patient consent Obtained.

Ethics approval Ethical approval for this secondary data analysis was obtained from the London School of Hygiene and Tropical Medicine ethics committee.

Provenance and peer review Not commissioned; externally peer reviewed.

Data sharing statement The dataset was compiled from databases provided by the DHS programme; https://www.dhsprogram.com/Data/

Open Access This is an Open Access article distributed in accordance with the Creative Commons Attribution Non Commercial (CC BY-NC 4.0) license, which permits others to distribute, remix, adapt, build upon this work non-commercially, and license their derivative works on different terms, provided the original work is properly cited and the use is non-commercial. See: http://creativecommons.org/ licenses/by-nc/4.0/

(c) Article author(s) (or their employer(s) unless otherwise stated in the text of the article) 2018. All rights reserved. No commercial use is permitted unless otherwise expressly granted. 


\section{REFERENCES}

1. Ronsmans C, Graham WJ. Lancet Maternal Survival Series steering group. Maternal mortality: who, when, where, and why. Lancet 2006;368:1189-200.

2. Kyei-Nimakoh M, Carolan-Olah M, McCann TV. Access barriers to obstetric care at health facilities in sub-Saharan Africa-a systematic review. Syst Rev 2017;6:1-17.

3. Hussein J, Kanguru L, Astin M, et al. The effectiveness of emergency obstetric referral interventions in developing country settings: a systematic review. PLoS Med 2012;9:e1001264-12.

4. Campbell OM, Calvert C, Testa A, et al. The scale, scope, coverage, and capability of childbirth care. Lancet 2016;388:2193-208.

5. Moyer CA, Mustafa A. Drivers and deterrents of facility delivery in sub-Saharan Africa: a systematic review. Reprod Health 2013;10:40.

6. Montagu D, Yamey G, Visconti A, et al. Where do poor women in developing countries give birth? A multi-country analysis of demographic and health survey data. PLoS One 2011;6:e17155-8.

7. Gabrysch S, Campbell OM. Still too far to walk: literature review of the determinants of delivery service use. BMC Pregnancy Childbirth 2009;9:34.

8. Ishola F, Owolabi O, Filippi V. Disrespect and abuse of women during childbirth in Nigeria: A systematic review. PLoS One 2017;12:e0174084-18.

9. Bohren MA, Hunter EC, Munthe-Kaas HM, et al. Facilitators and barriers to facility-based delivery in low- and middle-income countries: a qualitative evidence synthesis. Reprod Health 2014;11:71.

10. Benova L, Macleod D, Radovich E, et al. Should I stay or should go?: consistency and switching of delivery locations among new mothers in 39 Sub-Saharan African and South/Southeast Asian countries. Health Policy Plan 2017;32:1294-308.

11. Berhan $Y$, Berhan A. A meta-analysis of socio-demographic factors predicting birth in health facility. Ethiop J Health Sci 2014;24:81.

12. Say L, Raine R. A systematic review of inequalities in the use of maternal health care in developing countries: examining the scale of the problem and the importance of context. Bull World Health Organ 2007;85:812-9.

13. Kebede A, Hassen K, Nigussie Teklehaymanot A. Factors associated with institutional delivery service utilization in Ethiopia. Int $J$ Womens Health 2016;8:463-75.

14. Koblinsky M, Matthews Z, Hussein J, et al. Going to scale with professional skilled care. Lancet 2006;368:1377-86.

15. Moyer CA, Dako-Gyeke P, Adanu RM. Facility-based delivery and maternal and early neonatal mortality in sub-Saharan Africa: a regional review of the literature. Afr J Reprod Health 2013;17:30-43.

16. Magadi MA, Agwanda AO, Obare FO. A comparative analysis of the use of maternal health services between teenagers and older mothers in sub-Saharan Africa: evidence from Demographic and Health Surveys (DHS). Soc Sci Med 2007;64:1311-25.
17. Mills TA, Lavender T. Advanced maternal age. Obstet Gynaecol Reprod Med 2011;21:107-11.

18. Dyer SJ. The value of children in African countries: insights from studies on infertility. J Psychosom Obstet Gynaecol 2007;28:69-77.

19. Bulletin of the World Health Organisation. Motherhood or nothing; the agony of infertility [Internet]. 2010 http://www.who.int/bulletin/ volumes/88/12/10-011210/en/ (cited 2017 Sep 10).

20. Rouchou B. Consequences of infertility in developing countries. Perspect Public Health 2013;133:174-9.

21. Hashim N, Naqvi S, Khanam M, et al. Primiparity as an intrapartum obstetric risk factor. J Pak Med Assoc 2012;62:694-8.

22. Thaddeus S, Maine D. Too far to walk: maternal mortality in context. Soc Sci Med 1994;38:1091-110.

23. ICF International. The DHS Program; Demographic and Health Surveys; DHS Methodology [Internet]. http://dhsprogram.com/ what-we-do/survey-types/DHS-Methodology.cfm (cited $2016 \mathrm{Jul}$ 28).

24. Footman K, Benova L, Goodman C, et al. Using multi-country household surveys to understand who provides reproductive and maternal health services in low- and middle-income countries: a critical appraisal of the Demographic and Health Surveys. Trop Med Int Health 2015;20:589-606.

25. Benova L, Macleod D, Footman K, et al. Role of the private sector in childbirth care: cross-sectional survey evidence from 57 low- and middle-income countries using Demographic and Health Surveys. Trop Med Int Health 2015;20:1657-73.

26. Pullum T, Schoumaker B, Becker S, et al. An assessment of DHS estimates of fertility and under-five mortality: Prepared for 28/08/2013 International Population Conference of the IUSSP [Internet]. 2013 http://iussp.org/sites/default/files/event_call_for papers/Pullum Schoumaker Becker Bradley IUSSP 2013.pdf.

27. Bradley SEK, Croft TN, Fishel JD, et al. Revising unmet need for family planning, DHS Analytical studies 25. Calverton, Maryland, USA: USAID, 2012

28. The DHS Programme, USAID. Protecting the Privacy of DHS Survey Respondents [Internet]. http://dhsprogram.com/What-We-Do/ Protecting-the-Privacy-of-DHS-Survey-Respondents.cfm (cited 2016 Aug 23).

29. Stephenson R, Baschieri A, Clements S, et al. Contextual influences on the use of health facilities for childbirth in Africa. Am J Public Health 2006;96:84-93.

30. Shaw D, Guise JM, Shah N, et al. Drivers of maternity care in highincome countries: can health systems support woman-centred care? Lancet 2016;388:2282-95.

31. Ezeh AC, Bongaarts J, Mberu B. Global population trends and policy options. Lancet 2012;380:142-8.

32. Zabin LS, Kiragu K. The health consequences of adolescent sexual and fertility behavior in sub-Saharan Africa. Stud Fam Plann 1998;29:210-32. 